\title{
Cosmovisión indígena de los pueblos de Izalco, Nahuizalco y Santo Domingo de Guzmán, en torno a la construcción histórica de los derechos humanos de los pueblos originarios de El Salvador
}

\author{
The indigenous world view of the peoples of Izalco, Nahuizalco and Santo \\ Domingo de Guzmán in view of the historical construction of the indigenous \\ peoples' human rights in El Salvador
}

\author{
Marcelino Rodolfo Rojas \\ Melissa Alejandra Zepeda ${ }^{2}$ \\ Francisco Enrique Santos ${ }^{3}$ \\ José Orión Castellón ${ }^{4}$

\section{Resumen}

El presente artículo es el resultado final de un proyecto de investigación cuyo objetivo fue identificar la cosmovisión indígena de los pueblos de Izalco, Nahuizalco y Santo Domingo de Guzmán respecto de los derechos humanos de los pueblos originarios de El Salvador, su construcción histórica, así como la aplicación de sus derechos humanos en la actualidad, contrastando con la condición de vida de Ios indígenas de los pueblos de Izalco, Nahuizalco y Santo Domingo de Guzmán a partir del cumplimiento de sus derechos. La metodología en la cual se apoyó el estudio es la cualitativa, realizando visitas para obtener información por parte de informantes claves, ${ }^{5}$ desarrollando grupos focales, entrevistas no estructuradas y observación in situ, participando en algunas manifestaciones culturales con los indígenas de los diferentes caseríos de los municipios investigados y de los representantes de los

\section{Abstract}

This article is the final result of a research project which main objective was to identify the world view of the indigenous peoples in the towns of Izalco, Nahuizalco and Santo Domingo de Guzmán in relation to the human rights of the Native peoples in El Salvador and their historic development. In like manner, it depicts the application of said rights at present in contrast to their life conditions in the towns aforementioned based on the exercise of their rights. The qualitative method was used in this research; visits were made to collect information from key informers; focus groups were also organized; the non-structured interview and in situ observations were used by participating in some of the cultural activities with the leaders and the indigenous people from the different villages in the studied municipalities. In summary, the main thesis is that El Salvadorean

\footnotetext{
'Docente de Filosofía de la Escuela de Antropología de la Universidad Tecnológica de El Salvador (Utec).

${ }^{2}$ Estudiante de la Licenciatura en Antropología de la Utec.

${ }^{3}$ Estudiante de la Licenciatura en Antropología de la Utec.

${ }^{4}$ Estudiante de la Licenciatura en Antropología de la Utec.

${ }^{5}$ Previamente se realizaron las gestiones necesarias para ser recibidos en dichos municipios.
} 
pueblos indígenas. En síntesis, la tesis principal es que las autoridades de El Salvador no están cumpliendo con los derechos humanos de los pueblos originarios en torno a la propiedad de los territorios donde habitan, a su identidad y su lengua, y en definitiva en torno a los derechos humanos relativos a la calidad de vida económica, política y cultural. ${ }^{6}$ Se logró identificar que este hecho ha sido, por parte de los pueblos originarios, un mal y una causa de lucha constante hasta la actualidad.

De acuerdo con los testimonios, estos permiten claramente apreciar cómo esta población de los pueblos originarios ha sido perjudicada de muchas formas, desde arrebatarle sus tierras, sus vidas, el no contar con las condiciones sociales de vida más apropiadas hasta el simple hecho de apropiarse de su identidad patrimonial tangible.?

Entre las principales causas que provocan la violación de los derechos humanos de la población indígena está el poco conocimiento que han adquirido los pueblos originarios sobre los derechos humanos que las leyes internacionales y nacionales establecen. También, la violencia socioestructural es un factor de gran relevancia, pues a partir de esta falta de cumplimiento del Estado de El Salvador se irrespetan los derechos de esta población y, por ende, se les ha sometido a una condición de vida critica, desde lo económico, político, social hasta lo cultural.

Por lo tanto, se propone realizar capacitaciones en relación con los derechos humanos de los pueblos originarios y de los derechos establecidos en la Constitución de la República de El Salvador, y hacer convenios con medios de comunicación para que presenten la forma de vida de la población indígena y, a partir de esto, gestionar proyectos de rescate y valoración de los derechos humanos de los pueblos originarios.

\section{Palabras clave}

Indígenas - Situación legal - El Salvador; Conflictos étnicos - El Salvador; Culturas indígenas - El Salvador activities are not complying with the human rights of the indigenous peoples in terms of the lands where they live, their identity, their language, and the quality of their political, cultural and economic life. This fact has been and still is, a constant element in the ongoing struggle of the indigenous peoples.

Based on their testimonies, the native peoples have been wronged in several manners: from the unlawful appropriation of their lands and the lack of adequate social conditions of life, to the appropriation of their tangible inherited identity

One of the main reasons for the violation of the human rights of the indigenous peoples is the lack of knowledge they have on what both national and international laws establish. The sociostructural violence is yet another relevant factor; the Salvadorean State has failed to comply with these laws and, as a consequence, the rights of this population have been disrespected; therefore, they have been subjugated to a critical life condition, economically, politically, socially and even culturally speaking.

Hence, a series of training has been suggested in relation to the human rights of the Native peoples and the rights established in the Constitution of the Republic of El Salvador. Another recommendation has been to create agreements with the mass media for the dissemination of the lifestyle of the indigenous people and to manage projects to rescue and value their human rights.

\section{Keywords}

Natives/indigenous - legal status - El Salvador: ethnic conflicts - El Salvador; Indigenous/Native cultures - El Salvador

\footnotetext{
6 Por parte del grupo de investigador, se constató que se están violando los derechos humanos de los pueblos originarios, por parte del Estado de El Salvador y de sus autoridades; de las personas ladinas, como ellos los llaman, y por personas que tienen conocimiento de los valores que tiene el patrimonio histórico, entre estos, aquellos que conservan las cofradías indígeneas.

Se refiere al robo de piezas arqueológicas e imágenes religiosas.
} 


\section{Introducción}

Entre los pueblos indígenas de El Salvador se incluyen a los pueblos nahuat-pipiles, lencas y kakawira o cacaoperas y otros. No obstante la población indígena salvadoreña históricamente ha sido invisibilizada y marginada por parte de las distintas instituciones del Estado salvadoreño. Estas han mantenido alejadas a las poblaciones indígenas de la tenencia de las tierras, del poder político y de la riqueza económica.

La problemática de la identidad salvadoreña y su cosmovisión respecto de los derechos humanos de los pueblos originarios de El Salvador es el punto de enfoque que precisamente se desarrolló en esta investigación. Se plantearon preguntas como ¿por qué es necesario indagar sobre los pueblos indígenas y sus derechos como seres humanos?, ¿cuáles son hoy las condiciones sociales y materiales en las que viven los pueblos indígenas en estudio?, ¿por qué causas se ha invisibilizado sus derechos humanos antes y después del levantamiento indígena de 1932?, ¿por qué razón la población salvadoreña no se considera indígena?, ¿cuáles son sus actuales condiciones de vida? y, principalmente, ¿cuál es la cosmovisión que tiene el pueblo indígena sobre sus derechos humanos?

En cuanto al lugar de investigación, se delimitó en tres pueblos de la zona occidental de El Salvador; y se han usado como criterios de selección, de estos sujetos de estudio, los siguientes: Izalco, viéndolo desde el punto de vista jurídico, por la declaración de la alcaldía del común; Nahuizalco, por la injusticia social, la escasez y la violencia estructural que recibe la población indígena; y Santo Domingo de Guzmán, por el rescate de su identidad, es decir, su lengua nahuat, y la inserción religiosa, que también juega un papel importante en el respeto de sus derechos.

\section{Caracterización de los pueblos indígenas de Nahuizalco, Izalco y Santo Domingo de Guzmán}

Los pueblos investigados se ubican específicamente en la zona occidental de El Salvador; hacemos referencia a Nahuizalco, Izalco y Santo Domingo de Guzmán, donde hay presencia de población indígena.

Nahuizalco es una población indígena que vive diezmada por la violencia, el miedo, la vergüenza y sobre todo marcada por una lucha de subsistencia, por las injusticias que provienen desde las instituciones de gobierno, municipales, sociales y religiosas, que la marginan por el simple hecho de ser indígena.

En Izalco, su población indígena se ve marcada primero por un impulso y fortalecimiento en torno al rescate identitario de sus apellidos, de sus tradiciones, de su forma de ver el mundo, promovido desde la municipalidad con fines turísticos. Sin embargo, visto desde otra perspectiva, la certificación de la Alcaldía del Común como alcaldía 163 por el Instituto Salvadoreño de Desarrollo Municipal (Isdem) creó un peso sociopolítico en la forma de gobierno ancestral, acerca de la imagen del indígena; y sobre todo de sus tradiciones, pero separando las formas ancestrales de las celebraciones de sus verdaderos celebrantes indígenas y de su antiguo origen precolombino.

Santo Domingo de Guzmán: la situación como indígenas en este municipio es muy interesante, porque la población vive en unidad a pesar de sus diferencias religiosas, ya que el $90 \%$ es evangélica y el $10 \%$ católica. A pesar de esta diversidad religiosa, no se ha generan divisiones, aunque sí diversos cambios en sus tradiciones y en su cosmovisión. Todos ellos coinciden en la importancia del rescate de su idioma, el náhuat, el cual ha generado una rehabilitación de su identidad, permitiendo la apertura de un centro llamado "La Cuna Náhuat", donde los niños indígenas pueden estudiar y a la vez aprender el náhuat.

\section{Invisibilización de los pueblos indígenas}

El censo poblacional realizado por la Dirección General de Estadística y Censos (2007), promovido por el gobierno de El Salvador de aquellos años, es un reflejo del imaginario colectivo de los salvadoreños que rechazan su identidad indígena, generando una deuda política más a los pueblos indígenas. En El Salvador, históricamente se ha vivido en una constante lucha entre su origen indígena y el deseo de hacer desaparecer su identidad, reaccionando de una manera violenta hacia lo que se considera "incivilizado"; en este caso, el ser considerado indígena o perteneciente a los pueblos originarios. Este hecho, ser considerado indígena, es un estigma social con malas consecuencias económicas, políticas y culturales, en particular para las personas étnicamente indígenas que buscan evitar tal estigma, y, además, para los mismos pueblos originarios. 
En la actualidad, en los mismos pueblos originarios de El Salvador existe la duda existencial acerca de su identidad étnica, construida históricamente por parte de una sociedad considerada "moderna", y que históricamente ha reprimido a dichos pueblos originarios: por ejemplo, "en enero de 1932 fueron masacrados más de 25.000 o 30.000 indígenas" (Anderson, 2001). Esa masacre fue el punto de inflexión que abrió el camino a la discriminación y a la invisibilización de estos pueblos. Esta opresión y represión a los pueblos originarios en EL Salvador, hasta el día de hoy, es continua, viviendo estos en el miedo, la zozobra, la marginación y la exclusión de la participación de todo proceso de desarrollo, no solo del Gobierno, sino también de las instituciones no gubernamentales, religiosas, y aun dentro de su misma comunidad.

\section{Reconocimiento de los pueblos indígenas}

De acuerdo con la Asamblea Legislativa de El Salvador (2014), el 12 de junio del 2014 se ratificó la reforma al artículo 63, en el que "El Salvador reconoce a los pueblos indígenas y adoptará políticas a fin de mantener y desarrollar su identidad, étnica y cultural, cosmovisión, valores y espiritualidad".

Este artículo abrió las puertas a la visibilización de la identidad indígena, y a lucha, como pueblos originarios, por el rescate de sus derechos, económicos, políticos y culturales, pues anteriormente no se reconocía la existencia de estos, por ende no existían legalmente dichos pueblos. Lo que significaba que no gozaban de ningún derecho como pueblo originario, infringiendo con ello, por parte del Estado salvadoreño, el Artículo 2 de la declaración de las Naciones Unidas (2008) sobre los derechos de los pueblos indígenas, el cual dicta que "Ios pueblos y los individuos indígenas son libres e iguales a todos los demás pueblos y personas y tienen derecho a no ser objeto de ningún tipo de discriminación en el ejercicio de sus derechos, en particular la fundada en su origen o identidad indígena".

A raíz de esta declaración legislativa de la existencia de los pueblos originarios de El Salvador, uno de los pasos importantes posteriores consistió en el reconocimiento de la existencia e identidad de los pueblos indígenas a través del Isdem (2015), que reconoció como alcaldía 263 a la comunidad indígena de Izalco. El Alcalde del Común es el representante de más de 36 cofradías, cada una con su mayordomo, cuyo voto determina quién es el alcalde, cumpliendo así con el Artículo 3, que afirma que "los pueblos indígenas tienen derecho a la libre determinación. En virtud de ese derecho determinan libremente su condición política y persiguen libremente su desarrollo económico, social y cultural" (Naciones Unidas, 2008).

\section{Secuelas históricas de la invisibilización y marginación de los pueblos indígenas}

Los indígenas, históricamente invisibilizados, excluidos y políticamente sometidos, hasta el día hoy, experimentan el miedo que la misma alta clase política salvadoreña les ocasionó en el pasado. Por ejemplo, el asesinato de mucha de la población indígena debido a la acusación por parte del Estado salvadoreño de participar con el Partido Comunista en la rebelión de 1932. Este miedo por parte de los pueblos indígenas, inculcado por la clase política, se evidenció en la campaña electoral del 2009, en la que el partido de derecha argumentaba que, si se votaba por la izquierda, volvería a pasar con los indígenas lo mismo que en el año 1932. Además, según uno de los informantes clave, el señor Sánchez, "por eso ahora a la edad que tengo, no voy a la política, tengo miedo". ${ }^{8}$

\section{Un pasado histórico de invisibilización y exterminio}

La invisibilización y desaparición de los pueblos originarios comenzó en la época colonial, cuando se impulsaron procesos de mestizaje y ladinización que llevaron al debilitamiento de las comunidades indígenas en El Salvador. Estos procesos se intensificaron en la época posterior a la Independencia y fueron principalmente promovidos por los gobiernos liberales. Dos medidas se encargaron de dar un golpe mortal a los pueblos indígenas. Por un lado, la expropiación, a favor de los ladinos liberales, de las tierras comunales y los ejidos preservados hasta entonces para los indígenas. Y, por el otro, la Ley contra la vagancia, que obligaba a trabajar en las fincas a todos los que no tenían tierras. Estas políticas fueron apoyadas con la creación de la Policía Rural, que obligó a cumplirlas a rajatabla. Así se despojó a los indígenas de sus tierras y se les convirtió en proletarios al servicio de los terratenientes, lo que supuso la desintegración de sus comunidades y el debilitamiento de su identidad étnica.

\footnotetext{
8 Entrevista realizada en la presente investigación.
} 
La exclusión política de los indígenas no fue solo en la sociedad, sino también dentro de las mismas familias de los que se hacen participes de las luchas sociales o políticas, por ejemplo, según palabras de un indígena: “Cuando yo me declaré, es decir, me di color, mi familia, que eso me duele mucho, mi mamá, mis hermanas, todas me discriminaron por mostrar afinidad a un partido político".

Además, la masacre de 1932 no fue la única que trató de intimidar, callar y hacer desaparecer al indígena salvadoreño, ocurrieron otras como las de El Carrizal, en Nahuizalco, y Las Hojas, en San Antonio del Monte.

Según el testimonio de otro indígena "han querido, aunque hoy se ha calmado un poco, vender la idea del mentado comunismo, que a través de la historia nosotros nos hemos venido dando cuenta de que esa palabra simplemente la ocuparon para seguir manoseando, intimidando a nuestros abuelos, para que de una manera u otra, les penetrara ese miedo y ya no pudieran seguir en la lucha".

\section{Método}

En la investigación se aplicó la metodología cualitativa, dentro de la cual se realizaron visitas in situ con observación participante y entrevistas no estructuradas para obtener información por parte de los informantes claves, con los que se hizo gestión para ser recibidos en los pueblos originarios seleccionados. Además, la investigación se desarrolló en etapas que fueron controladas por los miembros del equipo según se delegaron las distintas actividades.

Además, se decidió que las etapas de investigación se dividieran de la siguiente forma:

Informarse. En esta etapa el equipo seleccionó el tema y luego se informó de cuales han sido los últimos acontecimientos con respecto al tema y si existe o no campo abierto a investigar. Se informó sobre posibles lugares a visitar y cómo contactar a informantes claves que puedan brindar los datos que necesitamos.

Planificar. El equipo organizó las primeras visitas in situ, en este caso, a tres municipios de la zona occidental del país: Izalco, Nahuizalco y Santo Domingo de Guzmán. Se determinó la metodología de investigación que se aplicaría, delimitación, la problemática y los objetivos de la investigación.
Decidir. Después de algunas visitas de campo, se seleccionó la información que se utilizó para la redacción del documento escrito, decidiendo si era necesario más visitas de campo o reforzar algún dato bibliográfico.

Ejecutar. Toda la información ya seleccionada fue organizada en el documento: marco histórico y teórico, justificación, hipótesis y solución, y expectativas sobre investigación. Esta etapa fue en la que el equipo invirtió más tiempo, pues es donde se construyó el informe escrito o documento final.

Controlar. El equipo verificó que cada etapa se hubiera desarrollado como se estableció al inicio de la investigación. Debió cerciorarse de que todas las actividades y tareas delegadas se desarrollaran con eficiencia. El documento fue revisado y modificado, dependiendo de las sugerencias hechas por el especialista que asesoró el proyecto de investigación.

Evaluar. La última etapa correspondió a evaluar los últimos detalles de la investigación, prepararse para la presentación de la investigación, además de proporcionar una copia del documento a los pueblos originarios estudiados.

\section{Informantes claves}

Nahuizalco: población indígena de los barrios El Rosario, El Calvario y San Juan.

Izalco: las cofradías de Las comadres, del Justo Juez de Cristo, de la Santa Cruz de Mayo y de Nuestra Señora de Belén.

Santo Domingo de Guzmán: población indígena del barrio El Centro.

\section{Técnicas de investigación}

En Nahuizalco se realizó un grupo focal con algunos indígenas de diferentes caseríos del municipio, y con la representante de los pueblos indígenas, para compartir sus testimonios sobre el trato que reciben por parte de los gobernantes y dirigentes económicos y políticos, y aun de los grupos delincuenciales ilícitos.

En Izalco se realizaron visitas, participando en algunas manifestaciones culturales del pueblo. Además, hubo una reunión con las mayordomas de las cofradías de Santa 
Teresa, San Miguel, Justo Juez, Nuestra Señora de los Dolores, que nos proporcionaron datos claves sobre la forma de vida de los indígenas de Izalco.

En Santo Domingo de Guzmán se visitó la cuna náhuat y a algunos indígenas, a los que se les hizo una entrevista abierta sobre el rescate del idioma nativo y cuál es la cosmovisión que tienen en cuanto al valor de sus derechos humanos como pueblos originarios de El Salvador.

\section{Instrumentos}

La investigación se centró en el desarrollo de grupos focales, observación participante y entrevistas no estructuradas, mediante visitas in situ a los municipios ya antes descritos. Se utilizaron algunos interrogantes referidos a determinar la condición de vida de la población indígena de Izalco, Nahuizalco y Santo Domingo de Guzmán a partir del cumplimiento de sus derechos humanos y de su propia cosmovisión o comprensión de sus derechos como pueblos originarios.

\section{Resultados}

Las siguientes exploraciones son el resultado de realizar varias visitas de campo en los municipios seleccionados, con la colaboración de informantes claves y con el objetivo de identificar si los derechos humanos de la población indígena se están ejecutando o no. Además, se indagó acerca de cuál es la cosmovisión de la población indígena en cuanto a su forma de vida, el bienestar de su familia, qué papel desempeñan en la sociedad y el punto principal de la investigación sobre qué entienden por derechos humanos y si conocen cuáles son sus derechos como pueblos originarios.

El municipio de Izalco es uno de los pueblos indígenas con más riqueza cultural, en cuanto a sus tradiciones que han realizado muchas generaciones. Las cofradías, Semana Santa y la presencia de población indígena es lo que fortalece su reconocimiento como pueblo vivo de El Salvador.

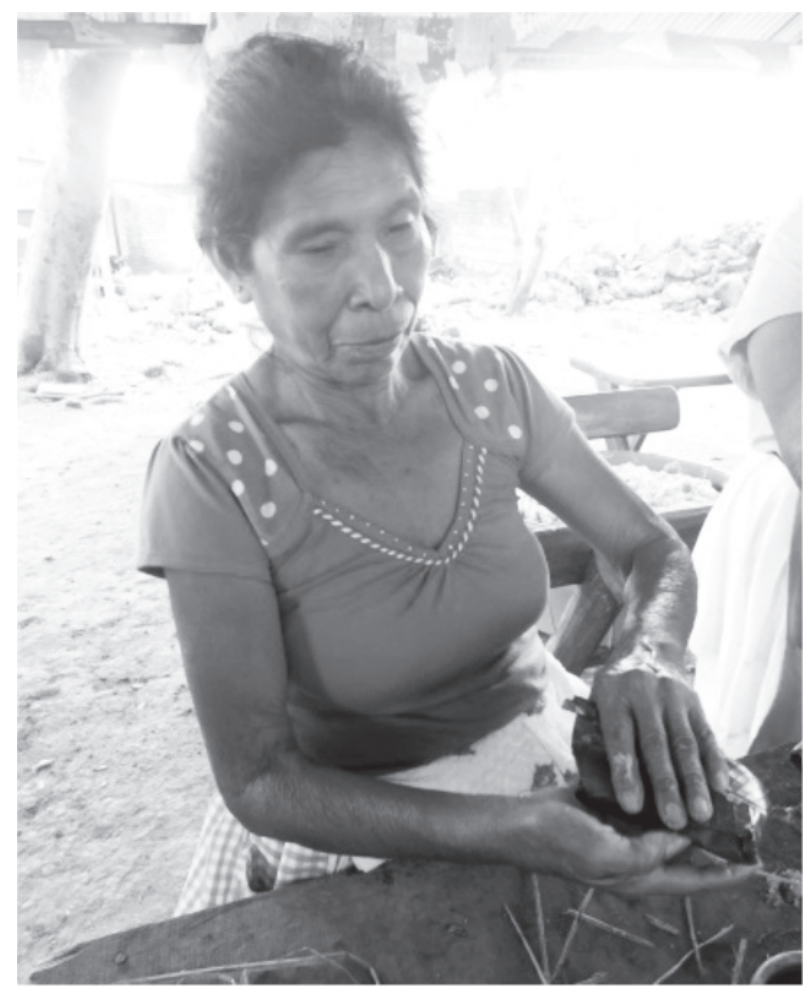

Cristina Musto, habitante del barrio Asunción del municipio de Izalco. Fotografía tomada por Orión Castellón, Izalco, 2017.

Entre los distintos indígenas que conservan las tradiciones está Cristina Musto, habitante del barrio Asunción de Izalco. Primero se indagó por sus condiciones de vida económica, política y cultural, y luego por el conocimiento de sus derechos humanos como parte de los pueblos originarios.

\section{A continuación se presenta la entrevista. ${ }^{9}$}

\section{¿Se siente parte del municipio de Izalco cuando asiste 0 participa en las cofradías que el pueblo realiza?}

Sí, yo soy nacida en Izalco y soy parte de las cofradías. Me gusta colaborar, cocinar, servir, estar desde tempranito en la casa donde va hacer la cofradía para ayudar en lo que uno pueda (...) Ya luego me gusta disfrutar, bailar, comer y convivir con las hermanitas que vienen.

\footnotetext{
9 Entrevistada: Cristina Musto; entrevistador: Francisco Santos; redacción de entrevista por Melissa Mayén.
} 
Precisamente, se observa que Cristina desempeña la labor de servir en estas tradiciones y, por ende, se siente parte de estos pueblos originarios; y que ha aprendido a valorar lo que hace. Cristina, además, confiesa cómo considera ella que "la gente de afuera" (no indígena) le valora a ella a partir de su forma de vida indígena:

La gente me ve de menos porque no tengo una casa propia y porque soy metiche (...). La gente de afuera de las cofradías son las que no me ven bien por lo que hago; eso sí, no es toda la gente (...). En las cofradías agarramos ambiente porque hemos convivido con todos hace años, aunque en veces hay malos entendidos entre los mismos que andamos en esto de las cofradías; y no me parece (...). Todos tenemos derecho a que nos incluyan, hasta el bolito que está tirado en la calle, que en veces llegan y se les recibe, porque ellos sirven para ir a enterrar a los muertos.

Interesante es el comentario que hace Cristina cuando habla que todos tienen derecho a la inclusión, porque de una manera está mostrando que tiene el conocimiento no solo de los derechos humanos que debe recibir, sino de que todos merecen ser incluidos.

Si vemos conjuntamente que recibir el respeto a sus derechos, a la igualdad de bienes, a sus pertenencias y calidad de vida como una perspectiva propiamente cultural, logramos identificar que este hecho ha sido una lucha constante de años. A partir de esto, se preguntó a Cristina si conocía cuáles son sus derechos, a lo que respondió lo siguiente:

Pues a tener trabajo, pero a nosotros, no, nos lo dan porque no nos vestimos bien, porque andamos en caites y chuquitos (...). En veces andamos, sí, una monedita en la bolsa; y no es, fíjese, porque no tengas ni un peso (...). No lo sacamos (el peso) porque no sabemos si vamos a tener para mañana; imagine lo perdemos (...). Yo he trabajado de lavar ropa, así de planchar; y la señora me daba el desayuno cuando iba, pero esa soy yo. Imagine los demás; les ha de costar tener un trabajito.

La gente que tiene su dinerito, a los que le dicen ladinos aquí, los que nos ven de menos, son los que dan trabajo de lavar o planchar, pero ya no nos pagan cabal como antes (...) Por eso ya no fui, yo.

\section{¿De qué otra forma considera que no están respetando sus derechos?}

Cuando nos han robado las imágenes de las cofradías, como la del Niño Dios, o cuando se llevaron la cruz; que eran imágenes que guardan lo bonito de las cofradías (...) Sepa Dios quién fue (...) Pero ya nadie hizo nada por hallarlas; y es cultura de aquí, de los pobres que cuidamos esas imágenes.

Básicamente logramos identificar un suceso importante y dos situaciones que están violentando sus derechos, por parte de las personas "civilizadas" o "Iadinas", como ellos los llaman, y por personas que conocen el valor que tiene el patrimonio inmueble que conservan estas cofradías, es decir, las imágenes. Se ha realizado un saqueo de imágenes a aquellas personas que ven como identidad cuidar $y$ venerar a un santo.

Por otra parte, es relevante conocer si en verdad la cosmovisión, en cuanto al concepto de derechos humanos que tienen los indígenas, es la misma que conocemos según las leyes universales. A partir de este análisis, preguntamos a Cristina si tiene conocimiento de lo que dicta la ley a favor de los pueblos originarios y si la declaración hasta el momento los ha beneficiado en algo., y respondió: "Yo no sé. Como yo no he visto eso; y la gente de aquí no sabe ¿Qué es eso? (...) yo no sé leer".

\section{¿Pero usted no apoya a ningún partido político?}

No, porque todo eso es mentira. Yo no ando viendo a quien seguir o creer (...). Aquí es 'el que trabajó comió y el que no trabajó no comió' (...). Nosotras somos indias, pero una tortilla no se la robamos a nadie; menos se la vamos a negar a alguien. Y la política les roba a los que somos indios.

Otra fuente de información fue la entrevista no estructurada realizada a la indígena doña Cristina Vásquez, habitante del barrio Cruz Galana y mayordoma de la cofradía de Belén. ${ }^{10}$

Lo principal de dialogar con doña Cristina fue determinar qué tanto conoce sobre sus derechos humanos. Nuestra labor

${ }_{10}$ Entrevistadores: Francisco Santos y Orión French, y, redacción de entrevista por Melissa Mayén. 
como investigadores era identificar si sus derechos se están haciendo valer, si no son víctimas de algún menosprecio.

Aquí los señores de la tercera edad en veces recibimos ayuda, nos dan una libra y media de arroz (...); dinero nunca, pero atención medica sí; y la salud es un derecho de todos, por lo menos para pasar consulta sí nos atienden y nos dan la medicina (...). La municipalidad sí está haciendo algo, pero en veces los cambios de partidos nos perjudican.

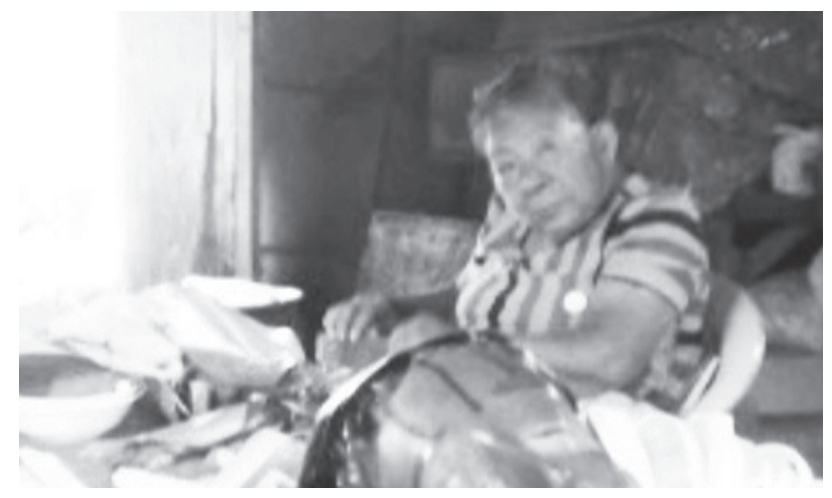

Cristina Vásquez, habitante del barrio Cruz Galana y mayordoma de la cofradía de Belén del municipio de Izalco. Fotografía tomada por Melissa Mayén, Izalco, 2017.

En cuanto al suceso del levantamiento indígena, es relevante indagar qué conocen o les han contado sobre ello. Recordemos que si nos remontamos al año de 1932 podemos identificar un hecho crucial del irrespeto hacia la población indígena, violentando uno de los máximos derechos se tienen como seres humanos: el derecho a la vida.

Del 32 no sé mucho, porque no lo viví (...); pero mi madre decía que mi papá, afligido, le decía que en cualquier momento iba a desaparecer o lo iban a ejecutar (...); y que la gente vivía en angustia porque a todos los andaban matando y les quitaban su terrenito.

Se desquitaban con la gente pobre. Ahora todavía se aprovechan de nosotros, lo que con esfuerzo tenemos nuestras cositas, por eso mejor no nos metemos con la política porque todo es engaño (...). Para el Alcalde del Común es prohibido meterse con cosas de partidos políticos; ellos deben velar por nosotros.
Ahora todavía somos víctimas cuando nos han robado la imagen del Niño Dios y del Divino Salvador de Mundo, que aunque no pierdo las esperanzas que un día se encuentren (...). De mi casa se llevaron el resplandor del Niño Dios, pero yo sé quién lo tiene; $y$ le he dicho que me lo enseñe, que yo sé que es el que tenía en mi casa, el que yo cuidaba; y no quiere, porque dice que no es ese (...). Cuando se llevaron al Niño Dios, bien recuerdo que fue un 23 de abril, el día de la procesión de los cristos (...). Un hombre vino y me preguntó si teníamos un cristo y le dije que sí; y si lo íbamos a sacar, y le dije sí y que para que quería saber. Me dijo: "Para ver si ayudo en algo" (...). Ya cuando terminó todo, nos dimos cuenta que la imagen del Niño Dios no estaba y lo reportamos a la Policía, pero después ya no hicieron nada.

Estos testimonios son los que permiten claramente apreciar cómo esta población ha sido perjudicada de muchas formas, desde arrebatarles la vida y no tener la condición de vida más apropiada hasta el simple hecho de apropiarse de su identidad patrimonial tangible.

Lo interesante es que básicamente la población, a pesar de todo, tiene como creencia el hecho de que todo lo que ellos padecen es porque Dios así lo quiere. A partir de esto se ha logrado determinar que la cosmovisión de los indígenas en cuanto a hacer valer sus derechos va más allá; es un acto de espiritualidad, de fe y de religión, más que una serie de leyes establecidas. Por eso Cristina Vásquez dice: "Yo sé que, primero Dios, un día todo va a salir a luz".

En cuanto a la relación con las personas allegadas a la religión católica, estas no ven a los indígenas de menos por pertenecer a las cofradías. Cristina Vásquez expresa lo siguiente:

Nos ven bien, porque hacemos algo antiquísimo; y como aquí el pueblo es el que ayuda (...). Hacer las cofradías es salir de lo habitual; y hay personas que siembran varias cosas para lograr hacer las cofradías, y en todo. Aquí ningún muerto se yede porque todos colaboramos.

Toda la gente ve bien las cofradías. Nadie deja de ayudar aunque sea con cincuenta centavos. 
Incluso la gente que no tiene qué comer, come en la cofradía (....). Tiene que ser, uno, popular con la gente, porque uno necesita de la gente siempre.

En la población de Nahuizalco es lamentable observar la realidad en la que vive la población, mediante las visitas realizadas al pueblo y a partir de un grupo focal desarrollado con algunos indígenas. Tal es el caso de Dorotea Flores viuda de Morales, ${ }^{11}$ que con mucha sinceridad nos compartió su testimonio en cuanto a la vida que tiene.

Lo principal que nos interesaba conocer era si ella siente que las personas la ven mal por su forma de vestir y de hablar. Claramente nos dijo que "no toda la gente nos ve mal por hablar así o por vestirnos así, solo que nos preguntan que dónde conseguimos los refajos, porque piensan que nos lo regalan; y no, nosotras las compramos".

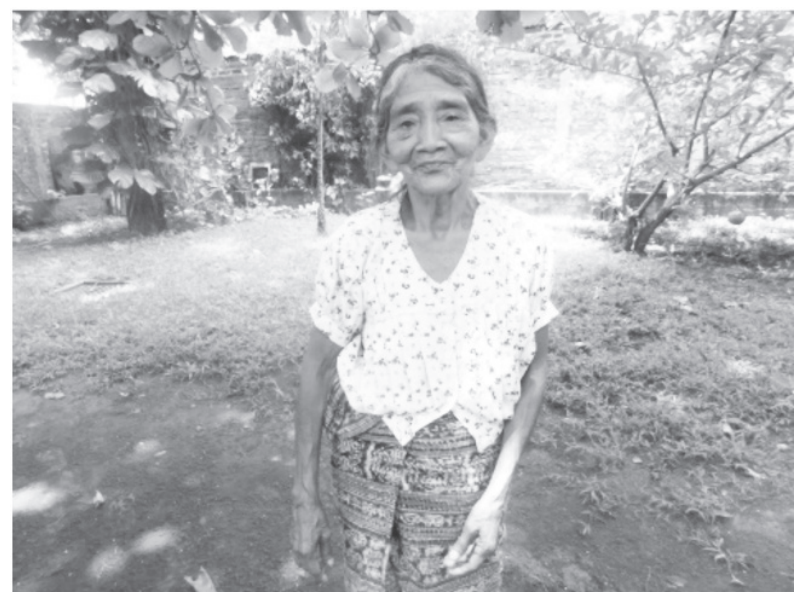

Dorotea Flores viuda de Morales, habitante del municipio de Nahuizalco. Fotografía tomada por Francisco Santos, Nahuizalco, 2017.

Además era importante identificar si la población indígena está siendo víctima de la violencia; y que de qué forma ellos consideran que les está afectando, pues en su mayoría están siendo amenazados de no dejarlos entrar a algunos lugares; y no solo a ellos, sino que a sus familiares también.

La gente mala nos odia, nos molesta, pero nosotros no hablamos nada (...); si no, ya no amanecemos. Y la gente mala, cuando en veces salimos, nos pregunta que a dónde vamos; que si a traer dinero, porque piensan que tenemos dinero (...). Es que ellos quieren quitarnos el dinero.
Lamentablemente, es más que evidente que la población indígena sí está siendo afectada por grupos ilícitos, a los que ellos le suelen llamar "gente mala". Incluso la representante de los pueblos originarios en un momento nos confesó que están hasta siendo despojados de sus tierras; y ellos, por miedo a ser asesinados, están cediendo sus terrenos. Pero no solamente están siendo violentados por grupos ilícitos, sino que incluso por empresas privadas que dicen trabajar por la gente cuando en realidad están acabando con lo único que tienen: sus tierras, o su madre tierra, como ellos la llaman.

Sin embargo, es interesante indagar cómo es que en realidad esta gente sobrevive. ¿Será que tienen un trabajo o viven de la caridad?

Cuando mi esposo estaba vivo teníamos nuestra ventecita de tombillas, pero como él ya no está, ya no lo hago (...). Vivimos de la caridad de la gente, del que salga en el día, porque hoy esta difícil conseguir dinero (...). A nosotros nos dicen que nos vayamos de donde vivimos; $y$ en veces pagan porque nosotros mismos trabajemos las tierras, pero es bien poco y el trabajo es pesado.

A partir de esa respuesta nos da la pauta para interrogarla si por causa de la violencia, no solo por querer arrebatarles las tierras, sino en cuanto a amenazas de muerte, algunas personas han tenido que desalojar sus casas y migrar a otro municipio o incluso fuera del país. Precisamente nos respondió de manera acertada.

Sí, varios se han ido. Unos están hay (ahí) por San Julián, por la violencia se han ido, sí por eso (...). Otros que están allá lejos ya no regresan, mejor se quedan. Por aquí está peligroso (...). Más que todo, los nietos, se van, porque a ellos les dicen más cosas, por eso ya no se quedan aquí; pero las abuelitas, las que nos ponemos los refajos, aquí nos quedamos.

A partir del testimonio de Dorotea, podemos identificar un hecho importante: cómo la población indígena se ha visto afectada por la violencia y, por ende, la alteración de sus derechos humanos.

\footnotetext{
${ }^{11}$ Entrevistador: Francisco Santos; y redacción de entrevista por Melissa Mayén.
} 
Preguntando por el acontecimiento histórico del levantamiento campesino de 1932, que afectó gran parte de la zona occidental de El Salvador, Dorotea respondió lo siguiente:

Yo no lo vi, pero mi mamá sí. Entonces le dije que me contara (...). Me dijo: “Te voy a contar cómo pasó porque no quiero que se pierda eso (...). Y como para la primera masacre del 32 mi mamá estaba embarazada, yo no estaba. Decía que a mi papá le llegaban a buscar, los comisionados les decían, o los comandantes, y a los que les llegaban a buscar los mataban en las cerraderas y los tiraban. En esos oyó (...) Entonces toda la gente tenía miedo, pero más los hombres; entraban a sus casas y se los llevaban a la fuerza.

La lucha por sobrevivir en esta sociedad, con las limitantes que se les presentan, es la principal causa de irrespeto de sus derechos; porque estas personas están teniendo una calidad de vida totalmente crítica, en escasez, con temores, enfermedades e incluso discriminación de la sociedad por considerarse indígenas.

Nos obstante, aunque las leyes salvadoreñas establecen, en la reforma de los artículos 63 y 169 de la Constitución del año 2014, su respaldo y respeto a los pueblos originarios, este derecho no se está cumpliendo por parte de las autoridades políticas ni por organizaciones no gubernamentales que, según Dorotea

están mal utilizando el nombre de los indígenas para beneficiarse de ellos, presentándose como personas que ayudan a los indígenas, porque muestran fotografías con ellos, aunque la realidad sea otra, ya que los están engañando, prometiéndoles seguridad y una calidad de vida mejor si se dejan tomar una foto.

El irrespeto se ve desde el momento que las alcaldías no gestionan proyectos para mejorarles la vida, según las entrevistas realizadas; que el docente que se limita a hablar de que todos somos indígenas y de que, por ende, debemos considerarnos parte de ellos; que el joven moderno ve mal a un señor con sombrero o en rara ocasión a una mujer con refajo, o, en última instancia, el niño que pregunta a su madre por qué el indígena anda vestido así, y su madre le niega que se acerque o salude a una persona así hasta el simple hecho de reconocer que la llamada "sociedad moderna o del siglo XXI" ve a la población indígena como incivilizados que no son parte de la nueva cultura.

Otra entrevista no estructurada realizada a Máxima Muso viuda de Rafael ${ }^{12}$ en el municipio de Nahuizalco arrojó la siguiente información.

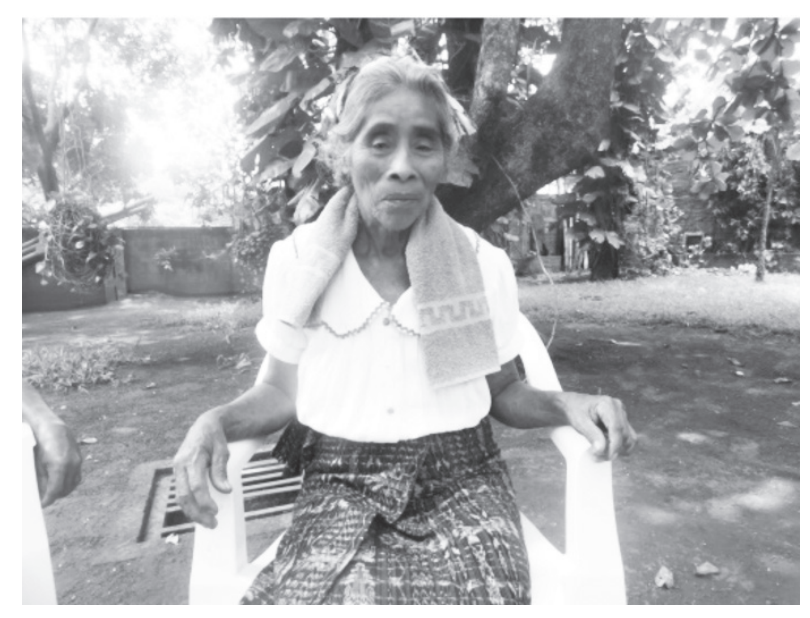

Máxima Muso viuda de Rafael, habitante del municipio de Nahuizalco. Fotografía tomada por Orion Castellón, Nahuizalco, 2017.

\section{¿Siente que algunas personas la miran mal por ser indí- gena? ¿Por vestirse y hablar distinto?}

Sí, hay personas que nos ven mal, en veces que hemos ido a San Salvador, pero así de paseo con los del grupo de Nahuizalco; y nos veían raro. Algunas personas nos decían que dónde nos dan los refajos, quién los regalaba eso (...). Estos refajos nosotras los compramos, nadie nos da nada, pero solo un refajo tengo ya y está desgastado. No sale ya para hacer la chonguita en la cintura.

\section{¿Cree que es difícil conseguir dinero es estos tiempo?}

Sí, bastante. Hoy ya no es como antes, nosotras no podemos trabajar; y como cuando mis hijos me ayudaban tenía cómo comer, pero hoy ya no, vivimos de lo que sale del día (...), algo que me regalen (...). Y como no aprendí a trabajar el tule, no puedo tener mi ventecita.

\footnotetext{
12 Entrevistador: Orión Frech y Melissa Mayén, y redacción de entrevista por Melissa Mayén.
} 


\section{¿De qué manera siente que la gente mala los molesta, aquí, en el pueblo?}

Cuando no nos dejan entrar en algunos lugares (...), cuando les dicen cosas malas a nuestros nietos (...); también cuando nos han dicho que nos vayamos de nuestras casitas pobres o cuando hemos visto algunas cosas que mejor callemos, si no, pueden matarnos.

\section{¿Por qué cree que muchos de ustedes se van del pueblo a otros municipios o tal vez a otro país?}

Porque es bien peligroso. Mucho temor hay en la gente y quizá les han quitado sus casas; y por eso se van (...). Como no hay trabajo se van los cipotes, si no, no hay qué comer.

\section{¿Conoce sus derechos como ser humano y cree que se lo están respetando?}

Sí, yo los conozco: tener qué comer y dónde vivir. Pero mi casa está algo levantada, porque un hijo mío la arregló (...), aunque cuando cocino me mojo, si llueve (...); pero la de mi vecina, la niña Ángela, se le están pudriendo, ya, las láminas (...); comer, en veces comemos, si hay; si no, hay que aguantar (...). Pero no hay respeto por nada de los derechos, nadie quiere ayudarnos.

\section{¿Vivió durante la masacre de 1932 o conoce alguna persona que la haya vivido?}

Yo no lo vi, y la mayoría que sí lo vivieron ya están muertos (...). Mi mamá decía que a toda la gente mataban; eran puños de gente a los que mataban (...). Se llevaban a los hombres, y todas las mujeres solas (...). Mi mamá me dijo que una tía, en esos días que estaba feo, iba a parir a su hijo y le tocó atenderse sola porque no podían salir de la casa para ir ayudarla (...). Era un temor hasta hablar en náhuat (...). Por eso, hoy ya ni hablamos de eso; nos da miedo que vengan y nos pase eso.

\section{Discusión}

Hablar de la identidad de El Salvador, su cultura, su trayectoria histórica y su gran proceso de inserción en el mundo globalizado es una temática relevante. Desde muchos años atrás se ha creado una falsa idea sobre cuál es la verdadera identidad que describe a los pueblos originarios salvadoreños; qué tanto se conoce la historia, conflictos y crisis que estos pueblos originarios han atravesado.
El mismo término indígena todavía es desconocido, invisibilizado e estigmatizado en el país, puesto que se nos ha inculcado que no somos indígenas y que los pueblos originarios solo son utilizados para incentivar el turismo, dejando de lado la identidad de los pueblos originarios.

A partir de esto, específicamente la investigación se enfocó en resaltar los derechos que estos pueblos merecen recibir, los cuales desde hace muchos años se han irrespetado. Es necesario dejar atrás la negación, la discriminación y el robo de su identidad, haciéndoles creer que no son parte de nuestra sociedad, como tal es el caso de los pueblos Nahuizalco, Izalco y Santo Domingo de Guzmán.

Precisamente la investigación se centró en estos pueblos originarios donde se identificó que se han irrespetado los derechos humanos a indígenas de la zona y a la cultura construida por estos.

Además, de acuerdo con la Declaración Universal de los Derechos Humanos de las Naciones Unidas, cada humano desde el momento en que nace adquiere ciertos derechos que lo acompañan por el resto de su vida, derechos que velan por el bienestar de cada uno de los integrantes de una sociedad, los cuales hay que respetar sobre cualquier circunstancia, por ejemplo, el derecho a la vida, a la educación, a la salud y muchos otros que son fundamentales para la vida del ser humano dentro de la sociedad.

Este trabajo de investigación se enfocó en los derechos humanos de los pueblos originarios de El Salvador, recalcando y profundizando en su cosmovisión, y en cómo las tendencias innovadoras han hecho de las raíces indígenas algo realmente invisible; así también, cómo estos han sido marginados por de la sociedad, o mejor dicho, cómo la sociedad los ha privado de sus propios derechos humanos. Los indígenas se han visto forzados a ser olvidados a tal punto que han llegado al autoexilio, y la sociedad los comenzó a ver como algo estético y atractivo para el turismo de El Salvador; y ha olvidado que son parte de la identidad salvadoreña.

Es necesario reconocer cómo su forma de vida se ha visto influenciada por causa de los cambios drásticos en la sociedad ante la situación económica, política y cultural, y la relevancia que le da el país a la preservación de su cultura.

Para terminar esta discusión, miles son los pensamientos que giran en torno a los derechos humanos en El Salvador, 
pero pocos se preguntan cuál es la visión que tiene la misma población indígena sobre sí mismos con respecto a los derechos humanos; y este fue el reto. Quizás no se alcanzó una comprensión completa, pero sí una aproximación, tratando de no imponer juicios de valor en sus testimonios ni tergiversándolos, sino presentando sus testimonios tal como los compartieron con los investigadores.

La investigación tuvo también como finalidad presentar la manera en que los hechos históricos influyeron tanto en el ámbito social, cultural y religioso en la población indígena de Izalco, Nahuizalco y Santo Domingo de Guzmán; y cómo se construyeron las bases para la invisibilizacion de los pueblos originarios. Sobre todo se indagó la cosmovisión de la población indígena respecto de los derechos humanos de los pueblos originarios.

En consecuencia, se recomienda realizar capacitaciones en los pueblos originarios en relación con los derechos de los pueblos originarios declarados por Naciones Unidas en 2008; y con la reforma del artículo 63 sobre los derechos presentes en la Constitución de la República de El Salvador; hacer convenios con medios de comunicación que presenten la forma de vida de la población indígena; y a partir de esto gestionar proyectos de rescate y valoración de los pueblos originarios.

Por otra parte, proponemos inculcar a las generaciones recientes y futuras la asistencia y participación en las tradiciones culturales que los pueblos conservan, ya que al participar en este tipo de manifestaciones culturales es más fácil identificar con minuciosidad los derechos que se les están violentando desde hace años atrás. Y concienciar a la población salvadoreña en el respeto a la equidad e igualdad desde los centros educativos.

\section{Conclusiones}

Uno de las principales orígenes de la violación de los derechos humanos de los pueblos originarios es el poco conocimiento que tiene población indígena respecto a ellos.

Los gobernantes y los dirigentes políticos, económicos y culturales constituyen un factor de gran relevancia, porque no están cumpliendo con estos derechos de los pueblos originarios declarados en Naciones Unidas y reconocidos en la Constitución de El Salvador, y por tanto ha sometido a la población indígena a una condición de vida crítica desde lo económico, político, social y cultural.

También, la invisibilizacion por parte de la sociedad actual hacia la población indígena es uno de los factores centrales por los cuales sus derechos no son tomados en cuenta, por ende se concluye que la falta de conciencia del ciudadano salvadoreño trajo un desarraigo histórico respecto de lo indígena, haciendo negar a las nuevas generaciones su propio origen indígena.

También se concluye que no se trata solo de realizar investigaciones, donde se conozca cómo en realidad está siendo tratada la población indígena; es más que eso, es buscar la manera de difundir estos escritos y analizar en profundidad las leyes que respaldan a los pueblos originarios, para posteriormente gestionar proyectos en pro de su rescate, su respeto y su valoración, evitando así que nuestra historia se pierda y las nuevas generaciones no conozcan qué fue lo beneficioso que se hizo por mantener vivos a nuestros ancestros, para que viviera su cultura y su herencia.

\section{Referencias}

Anderson, T. (2001). El Salvador, 1932: Ios sucesos políticos. San Salvador: Dirección de Publicaciones e Impresos, Concultura.

Asamblea Legislativa de El Salvador (2014). "Constitución de la República de El Salvador". Recuperado de www. asamblea.gob.sv/

Instituto Salvadoreño de Desarrollo Municipal (2015). "Certificación de la Alcaldía del Común de Izalco como alcaldía" 163. Recuperado de www.isdem.gob.sv/

Dirección General de Estadísticas y Censos (2007). "Censo de Población y Vivienda 2007". Recuperado de www.digestyc.gob.sv/index.../poblacion-y.../censo... poblacion.../poblacion-censos.html

Naciones Unidas (2008). "Declaración de las Naciones Unidas sobre los derechos de los pueblos indígenas". Recuperado de http://www.un.org/esa/socdev/unpfii/ documents/DRIPS_es.pdf 